\title{
A PHYSICIAN SURVEY OF THE EFFECT OF RELEVENCE OF DRUG'S BRAND NAME ON PHYSICIAN'S BEHAVIOUR
}

\section{CHIRAG B PANDYA}

\author{
B. Pharm, MBA, Freelancer Researcher \& Marketer, Gujarat, India
}

\begin{abstract}
This research aims to assess the effect of relevance of drug's brand name, on physician's prescribing behaviour.

Two brands were selected based on their representative markets' competitiveness and relevance of their names. 214physicians practicing under ambulatory care setting were surveyed to know their preference towards these brands and whether they would use these brands instead of their preferred brands, keeping other factors constant. Research findings indicate that, brand names related to their molecule names are perceived more memorable and meaningful. Such brands get higher share of prescriptions, keeping other factors constant.
\end{abstract}

KEYWORDS: Pharmaceutical Market, Marketing Management, Brand Name \& Brand Management

Received: Aug 05, 2017; Accepted: Aug 23, 2017; Published: Aug 29, 2017; Paper Id.: IJSMMRDOCT20171

\section{INTRODUCTION}

Drug advertising has been shown to affect physicians' prescribing behaviours. 'Drug advertising has become more aggressive as the Indian Pharmaceuticals Market is witnessing huge competition. For Instance, there are more than 30 brands of Atorvastatin, 30 brands of Telmisartan, 60 brands of Glimepiride + Metformin and 50 brands of Teneligliptin, which are generating business of more than $1 \mathrm{Cr}$ annually. ${ }^{2} \mathrm{In}$ such a highly competitive market, one important parameter to get differentiated is "Brand Name". A memorable and meaningful brand name offers many advantages. ${ }^{3}$ Although identifying 'Right' brand name is rigorously followed by pharma brand managers, little has been published about how the brand name which is related to the molecule name affects physicians' prescribing habits.

\section{METHODS}

Setting and Study Participants

We surveyed all 230 eligible practicing consulting physicians from various states of India about their prescribing habits between April and July 2017. Physicians were eligible if they were examining more than 15 patients a day. Physicians who were not frequent users of the molecules under the study were excluded. All responses to the study were anonymous.

Brand names for the study were selected on the following criterias 1) the markets of selected brands were highly competitive. (At least 25 brands with $>1 \mathrm{Cr}$ annual business) 2) the brand names were related to the names of molecules. Based on above criterias, we chose two brand names 1) Atorva (Atorvastatin) 2) Telma (Telmisartan). These brand names were related to their molecules and they were present in highly competitive markets. 


\section{Questionnaire}

We developed three part questionnaire, that assessed demographic characteristics, self-reported practice patterns, and attitudes towards brand name, that is related to the molecule name. The first part of the questionnaire assessed demographic characteristics, which included age, gender, no of patients/day and town class of practice. In the second part of questionnaire, respondents were asked to rate the extent (Low, Medium or High) to which they prefer brands Atorva and Telma. In the third part of questionnaire, respondents were asked to rate the extent to which they agreed with 9 statements regarding their attitude about importance of relevant brand names, from "strongly agree" to "strongly disagree" on a 5point liker scale. These statements regarding physicians' attitudes were chosen to know, whether the relevant brand name changes, prescribing habits of physicians keeping other factors constant. The questionnaire was pretested among 7 non participating physicians and revised to increase clarity.

\section{Analytical Methods}

Physicians were categorized as low, medium or high prescribers of brands, based on the second part of the questionnaire. To assess if relevant brand names alter physicians' brand preferences, we examined attitude of low and medium prescribers, towards relevant brand names keeping other factors constant based on the third part of the questionnaire.

\section{RESULTS}

Two hundred and thirty questionnaires were distributed; 214 (93\%) were completed and returned. The characteristics of low, medium and high prescribers were as follows:

Table 1: Characteristics of Low, Medium and High Prescribers of 'Atorva' \& 'Telma'

\begin{tabular}{|l|c|c|c|c|}
\hline & $\begin{array}{c}\text { Low Prescribers } \\
(\mathbf{a})\end{array}$ & $\begin{array}{c}\text { Medium Prescribers } \\
(\mathbf{b})\end{array}$ & $(\mathbf{a + b})$ & $\begin{array}{c}\text { High } \\
\text { Prescribers }\end{array}$ \\
\hline Total & $51(24 \%)$ & $94(44 \%)$ & $145(68 \%)$ & $69(32 \%)$ \\
\hline Mean Age & 45.2 & 41.1 & & 47.2 \\
\hline Gender & & & & \\
\hline Male & 37 & 67 & 104 & 53 \\
\hline Female & 14 & 27 & 41 & 16 \\
\hline
\end{tabular}

Among the 145 low or medium prescribers of the brands, 134(92\%) respondents found 'Atorva' \& 'Telma' as more memorable and meaningful brand names, compared to their preferred brands. 122(84\%) respondents agreed to prescribe 'Atorva' \&'Telma', instead of their preferred brands keeping other factors constant.

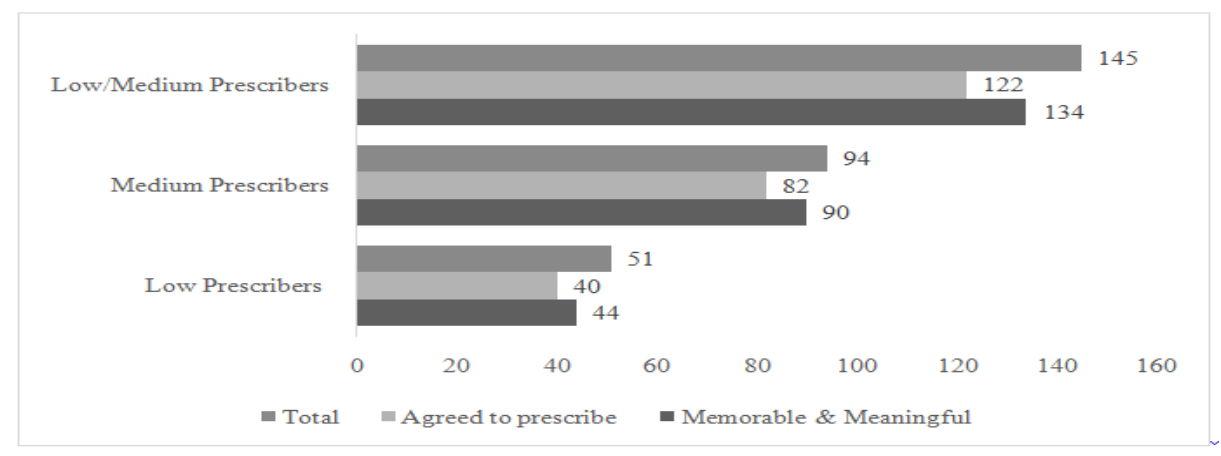

Figure 1: Low, Medium \& Low/Medium Prescribers' Attitudes towards Brand Names Which are Related to Molecule Names 
Among the 69 high prescribers of the brands, 67(97\%) respondents found 'Atorva' \& 'Telma' memorable and meaningful.

\section{CONCLUSIONS}

- Brand names that are related to molecule names are found more memorable and meaningful by prescribers, even though they are low or medium prescribers of those brands.

- Keeping other factors constant, brand names that are related to molecule names have higher chances of getting prescribed by prescribers, even though they are low or medium prescribers of those brands.

- Relevant brand names help to generate higher prescriptions in highly competitive markets

\section{REFERENCES}

1. Avorn J et al. (1982). Scientific versus commercial sources of influence on the prescribing behavior of physicians. Am J Med. $73(1): 4-8$.

2. AIOCD AWACS June 2017 dataset

3. Keller, K. L. (2013). Strategic Brand Management. Pearson Education Limited (p. 141) Harlow, England 
